\title{
A COMPARATIVE MAPPING OF ENZYMES INVOLVED IN HEXOSEMONOPHOSPHATE SHUNT AND CITRIC ACID CYCLE IN THE BRAIN*
}

\author{
Reinhard L. Friede, LaDona M. Fleming and Mechthilde Knoller \\ Mental Health Research Institute, University of Michigan, Ann Arbor, Michigan
}

(Received 15 November 1962)

Reports of preceding investigations (Friede, 1959a, 1961 $c$; Friede and Fleming, 1962) have contained detailed charts of the distribution of several enzymes in the brain. The purpose of this paper is to compare enzyme patterns with each other and to describe similarities and, particularly, differences of the patterns that were observed. The regional patterns in the brain of seven enzymes which are concerned with glucose metabolism were studied and compared. Most of the data were obtained from histochemical series from rhesus monkey and human brains. These were compared with tissue homogenate assays. The enzymes studied were cytochrome oxidase $f$ succinic dehydrogenase, DPN-diaphorase, TPN-diaphorase, malic dehydrogenase glucose-6-phosphate dehydrogenase, 6-phosphogluconic dehydrogenase and lactic dehydrogenase. In order to render this article more complete, some previously published data have been included.

\section{MATERIALS AND METHODS}

Because of difficulty in obtaining adequate human material, the systematic work reported in this study was done on rhesus monkey brains. Most of the observations were compared with observations on human material as it became available during the course of the study. The following material was used:

Monkey: Microscopic histochemical surveys were made by series for LDH, G-6-P, 6-PD, DPN-diaphorase, TPN-diaphorase, CYO and SD. Extensive spectrophotometric measurements of LDH were made from histochemical sections. SD, DPN-diaphorase, and G-6-P were assayed in homogenates from various regions and the data were compared with the histochemical staining gradients. Plans to assay all the nuclei of the monkey brain had to be discarded because the small size of the brain did not permit accurate macroscopical sampling of smaller nuclei.

Man: Random histochemical material was available for SD, LDH, CYO and G-6-P. The distribution of DPN-diaphorase was available from previous mappings (FrIEDE and FLEMING, 1962). In addition, G-6-P, DPN-diaphorase and SD were assayed in homogenates of seventeen representative regions from five normal human brains obtained 3.5 to 10 hours after death. The assay measurements were used for comparison with the histochemical gradations, as well as for comparison with each other (Table 1, line 6).

Also included are some observations on the distribution of MDH in the cat brain stem.

Methods: Complete details of methodology are given in a separate publication (FRIEDE, FLEMING and KNOLLER, 1963) in which histochemical methods were tested extensively by comparison with assays in tissue homogenates. At this time, it may suffice to indicate that the use of formalin-fixed material was an advantage for histochemical studies of DPN-diaphorase and LDH. When carried out under carefully controlled conditions, fixation prevented loss of these two enzymes from tissue blocks and sections; histochemical data obtained by spectrophotometric measurement of formazan were in excellent agreement with the data of assays of unfixed tissue homogenates. Attempts to elaborate and standardize fixation methods for the other enzymes studied have failed so far.

* This investigation is supported by U.S. Public Health Grant B3250.

$\uparrow$ Abbreviations used are: CYO, cytochrome oxidase; SD, succinic dehydrogenase; DPN, diphosphopyridine nucleotide; TPN, triphosphopyridine nucleotide; G-6-P, glucose-6-phosphate dehydrogenase; 6-PD, 6-phosphogluconic dehydrogenase; LDH, lactic dehydrogenase; CA, citric acid; HMP, hexose monophosphate; MDH, malic dehydrogenase. 
Extensive measurements of LDH were done in three monkey brains. Except for the media, the method was identical to that used for the measurement of DPN-diaphorase in formalin-fixed tissue sections (FRIEDE and FLEMING, 1962). It consisted essentially of incubating in the proper medium unmounted $30 \mu$ sections with constant agitation at $38^{\circ}$ for $1 \mathrm{hr}$, punching a disc of known volume, and extracting, and spectrophotometrically measuring, the formazan in the disc. For the other enzymes, loose $60 \mu$ sections of unfixed tissue were incubated in the media based on techniques published in the literature. Occasionally, $60 \mu$ sections of unfixed material were used for punching discs from which the formazan was extracted and measured spectrophotometrically; gradations of the enzyme reaction within a given section were like those observed in assays. However, the measurements in a large sampling of sections were not as consistent and reproducible as those for DPN-diaphorase and LDH.

\section{RESULTS}

\section{A. Similarities in the distribution of several oxidative enzymes in the brain}

Studies of histochemical series of seven enzymes in monkey brain revealed a striking similarity of the distribution of these enzymes, particularly in the nuclei of the medulla oblongata. A part of the large series of microscopic, histochemical data was confirmed with spectrophotometric measurements made from adjacent histochemical sections and with homogenate assays; the results were in excellent agreement. These patterns were extremely similar to those observed in previous mappings of guinea pig, cat and man. In fact, enzyme patterns in the medulla oblongata were identical among species, so that measurements of various enzymes from the species studied showed the same gradations among nuclei (Table 1).

TABLE 1.-COMPARISON OF PATTERNS OF OXIDATIVE ENZYME ACTIVITY AND CAPILLARIZA IION

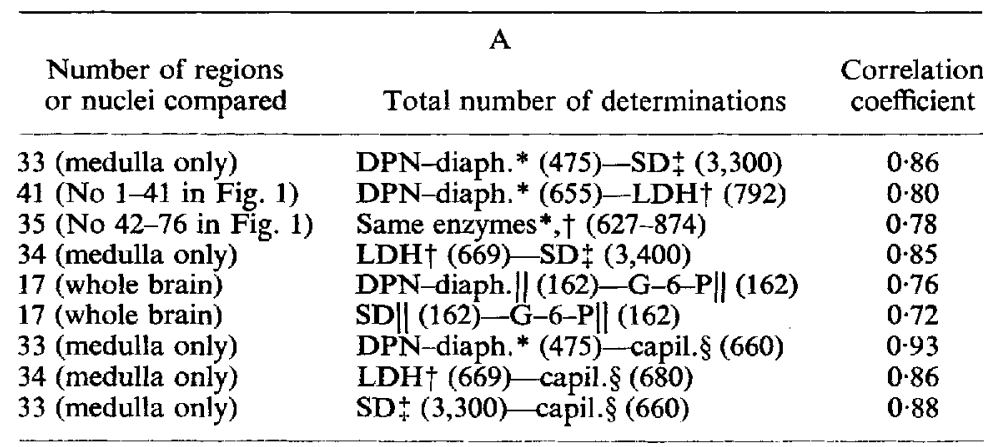

$\mathbf{B}$

Limits of reproducibility by the technique, as indicated by the correlation coefficients for measurements of lactic dehydrogenase in three monkeys $(133,134,144)$.

\begin{tabular}{|c|c|c|}
\hline $\begin{array}{l}43 \text { (whole brain) } \\
38 \text { (whole brain) } \\
49 \text { (whole brain) }\end{array}$ & $\begin{array}{l}\text { Monkey } 133, \text { monkey } 134 \\
\text { Monkey } 134 \text {, monkey } 144 \\
\text { Monkey } 133, \text { monkey } 144\end{array}$ & $\begin{array}{l}0.94 \\
0.89 \\
0.94\end{array}$ \\
\hline
\end{tabular}

Figure 1 shows a comparison of spectrophotometric measurements of DPN-diaphorase in the human brain,(FRIEDE and FLEMING, 1962) and LDH in the monkey brain (appendix). The extreme similarity of the patterns is evident. 


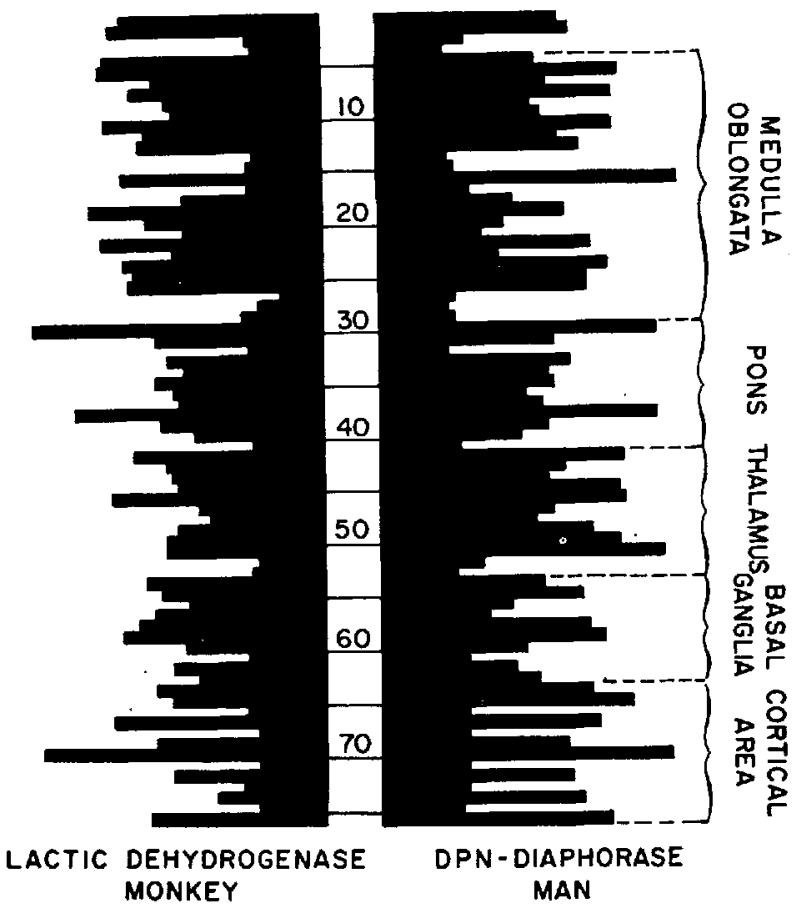

Fig. 1.-Comparison of the relative gradations of 1282 measurements of DPNdiaphorase in human brain (from FRIEDE and FLEMING, 1962) and 1666 measurements of LDH in monkey brain (from appendix, this paper). The nuclei represented can be identified by comparing the numbers in the centre column with the following list:

Medulla spinalis:

(1) columna grisea ventralis, (2) columna grisea lateralis, (3) lateral tracts, (4) dorsal tracts. Medulla oblongata:

(5) nucl. cuneatus medialis, (6) nucl. cuneatus lateralis, (7) nucl. tractus descend. $n$. trigemini (general region), (8) nucl. n. hypoglossi, (9) nucl. tractus solitarii, (10) nucl. reticularis, (11) nucl. vestibularis medialis, (12) nucl. vestibularis lateralis, (13) nucl. prepositus hypoglossi, (14) tractus pyramidalis, (15) corpus restiforme.

\section{Cerebellum.}

(16) nucl. dentatus, (17) substantia alba. Pons:

(18) nucl. reticularis, (19) nucl. n. abducentis, (20) griseum centrale, (21) nucl. coeruleus (and adjacent griseum centrale), (22) nucl. n. trigemini motorius, (23) nucl. parabrachialis, (24) nucl. parolivaris and $n$. olivaris superior, (25) nucl, reticularis Bechterew, (26) nucl. pontis, (27) tractus pyramidalis, (28) brachia pontis, (29) brachium conjunctivum.

\section{Midbrain:}

(30) colliculus inferior, (31) griseum centrale (ventral portion, caudal), (32) midline nuclei, (33) colliculus superior (laminae profundae), (34) regio $\mathrm{S}$ and nucl. mesencephalicus profundus, (35) griseum centrale (rostral, dorso- lateral portion), (36) griseum centrale (rostral ventromedial portion), (37) pretectal area, (38) nucl. n. oculomotorii, (39) nucl. ruber, (40) nucl. niger, (41) pendunculi cerebri.

\section{Thalamus:}

(42) nucl. anterior (dorsalis), (43) nucl. lateralis, pars anterior, (44) nucl. lateralis, pars ventralis, (45) nucl. dorsomedialis, (46) anterior midline nuclear group, (47) centre median, (48) midline nuclear group (deep transition into hypothalamus), (49) pulvinar, (50) nucl. geniculatus medialis, (51) nucl. geniculatus lateralis, (52) capsula interna, (53) tractus opticus.

Diencephalon (subthalamic and basal telencephalic centres):

(54) tubercinereum (lateral portion), (55) nucl. subthalamicus, (56) zona incerta, (57) peduncular zone of nucl. intercalatus, (58) nucl. caudatus (caput), (59) putamen, (60) pallidum internum, (61) capsula interna, (62) claustrum, (63) amygdala.

\section{Cortex:}

(64) percentral motor cortex, laminae II-IV, (65) frontal pole, laminae II-IV, (66) same: substantia alba, (67) parietal cortex, laminae II-IV, (68) same: substantia alba, (69) insular cortex, (70) occipital cortex, lamina IV, (71) same: substantia alba, (72) temporal cortex, laminae II-IV, (73) same substantia alba, (74) deep temporal cortex, laminae II-IV, (75) same: substantia alba, (76) ammonshorn (total). 
The correlation coefficients of measurements of enzyme patterns and capillarization in various species are given in Table 1A. The nuclei were sampled either from the medulla oblongata only, or from the whole brain; along with Fig. 1, the table demonstrates the high degree of similarity among the various enzyme patterns, particularly in the medulla oblongata.

Some gross differences of enzyme distribution seem to occur phylogenetically in a caudo-cranial direction. The distribution of enzymes in the thalamus was somewhat different in monkey than in man (Fig. 1); this finding is in keeping with the even more striking difference between the rodent thalamus and the human thalamus (FRIEDE and Fleming, 1962).

\section{B. Differences in the cytological distribution of enzymes in gray matter}

While the over-all distribution of the enzymes was quite similar among most nuclei and regions of the brain, the various enzymes differed distinctly in cytological distribution. Most of the following data refer to monkey brain, but we have observed that the descriptions given are equally valid for man or cat.

Some nuclei of the brain contained relatively more enzyme activity per tissue

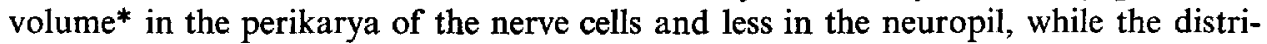
bution in other nuclei was reversed (FrIEDE, 1960b, 1961 c). However, if one compared the distribution of several enzymes in particular nuclei, it became evident that the enzymes differed in cytological distribution, and a relative order of the enzymes in regard to characteristic cytological gradations was observed. Enzymes involved in the hexosemonophosphate (HMP)-shunt usually were somewhat stronger in the nerve cell perikarya and somewhat weaker in the neuropil; while SD, and particularly CYO, were stronger in the neuropil and weaker in the perikarya. The other enzymes occupied an intermediary position between these extremes.

In comparing the patterns of all the enzymes we studied, the following order was obtained: G-6-P and 6-PD, LDH, DPN-diaphorase, TPN-diaphorase, MDH, SD and CYO. Those listed first were stronger in perikarya and weaker in neuropil; those listed last were vice versa. Conceivably, it is no coincidence that this order reflected approximately the natural metabolic order of the enzymes. The pattern of MDH was not strictly identical with that of SD, but this deviation of $\mathrm{MDH}$ distribution from that of other citric acid (CA) cycle enzymes was also observed microchemically by RoBINS and SMITH (1953).

These differences of pattern of cytological enzyme localization were observed throughout the central nervous system, but they were more readily recognized in some regions in which the anatomical arrangement facilitated comparison of neuropil and nerve cells. A few of these regions, described in detail, serve as typical examples:

Cerebellar cortex: In the molecular layer, marked activity of SD and CYO was distributed homogeneously throughout the neuropil in which no cytological details were discernible. The DPN-diaphorase reaction was somewhat less diffuse in the neuropil, and the thick proximal portions of the dendrites of Purkinje cells were clearly distinguishable. The LDH reaction was still less diffuse in the neuropil; there was a clear-cut demonstration of even the smallest arborizations of the Purkinje dendrites (Fig. 2); in addition, perikarya of glial cells had stronger enzyme activity than the

* Different conclusions are reached if measurements are based on fat-free dry weight, since lipid and water contents differ markedly for perikarya and neuropil (LowRY et al., 1954; see also discussion). 
neuropil (Fig. 2). The pattern for G-6-P was similar to that of LDH, although perhaps still weaker in the neuropil and stronger in perikarya and glial cells.

In the dense clusters of Bergmann's glia cells between the Purkinje cells very little, if any, activity of SD or CYO was observed. Some DPN-diaphorase activity was seen in these cells while there was a distinct reaction for LDH (Fig. 2) which occasionally permitted one to distinguish even the glial processes. A marked reaction for G-6-P was found in Bergmann's glia cells.

The reaction for CYO, SD, and for DPN-diaphorase per volume in the synaptic glomeruli of the granular layer was almost equal to that in the Purkinje cells. However, there was definitely less $\mathrm{LDH}$, and much less G-6-P activity in the glomeruli than in the Purkinje cells. The perikarya of the granular cells exhibited weak enzyme activity in general, but the gradient of enzyme activity between granular cells and glomeruli was largest for CYO and smallest for G-6-P.

Fascia dentata: The fascia dentata showed very little activity of SD or CYO in the layer of pyramidal cells*; marked activity was found in the molecular layer which was sharply divided into two laminae, the distal one having more enzyme activity than the proximal one (Fig. 3). There was some weak reaction for DPN-diaphorase in the pyramidal cells; for this enzyme, the division of two laminae in the molecular layer was still seen but the gradient was not as marked as for SD. The LDH reaction was distinct in the pyramidal cells; the molecular layer showed either no formation of laminae or, sometimes, a slightly stronger reaction in the proximal portion of the layer (Fig. 4). G-6-P activity was marked in the pyramidal cells (Fig. 5) and there was relatively weak activity in the molecular layer, often showing some increase in its proximal portion.

Cerebral cortex: The distribution of SD, CYO, MDH and DPN-diaphorase was homogeneous throughout the upper four laminae of the cerebral neocortex; the majority of pyramidal cells appeared as optically "empty" areas, with less reaction than that of the surrounding neuropil. In contrast, both the LDH and G-6-P reaction were slightly stronger in the pyramidal cells than in the adjacent neuropil. Similar patterns were seen in the central gray matter and in most other nuclei characterized by a diffuse distribution of enzyme activity in the neuropil, such as sensory nuclei in the brain stem, and certain thalamic nuclei (see also Figs. 13-15).

The gradient between two nuclei for a particular enzyme depended somewhat on the cytological distribution of that enzyme. For example, the over-all gradient between putamen (enzyme almost exclusively in neuropil) and pallidum (enzyme predominantly in perikarya) was smaller for G-6-P than for SD. This is shown in Fig. 6 where "average" assay patterns of SD, DPN-diaphorase and G-6-P in monkey brain were compared among types of nuclei selected on the basis of their prevalent cytological enzyme distribution (predominance of activity either in neuropil or perikarya). If, in this manner, nuclei of similar cytological patterns were averaged, smaller shifts of the relative ratios of enzyme activities became evident; these were superimposed but not readily recognizable on comparing the much larger over-all gradations among nuclei, such as in Fig. 1. Fig. 6 shows that the HMP-shunt enzymes

* These observations in monkey brains agreed with those in cat and man, but they differed from previous findings in the guinea pig (FRIEDE, 1960a), where SD was rather strong in this layer. This might reflect a species difference quite in contrast to the findings in the rest of our material, or else an unknown functional difference. 


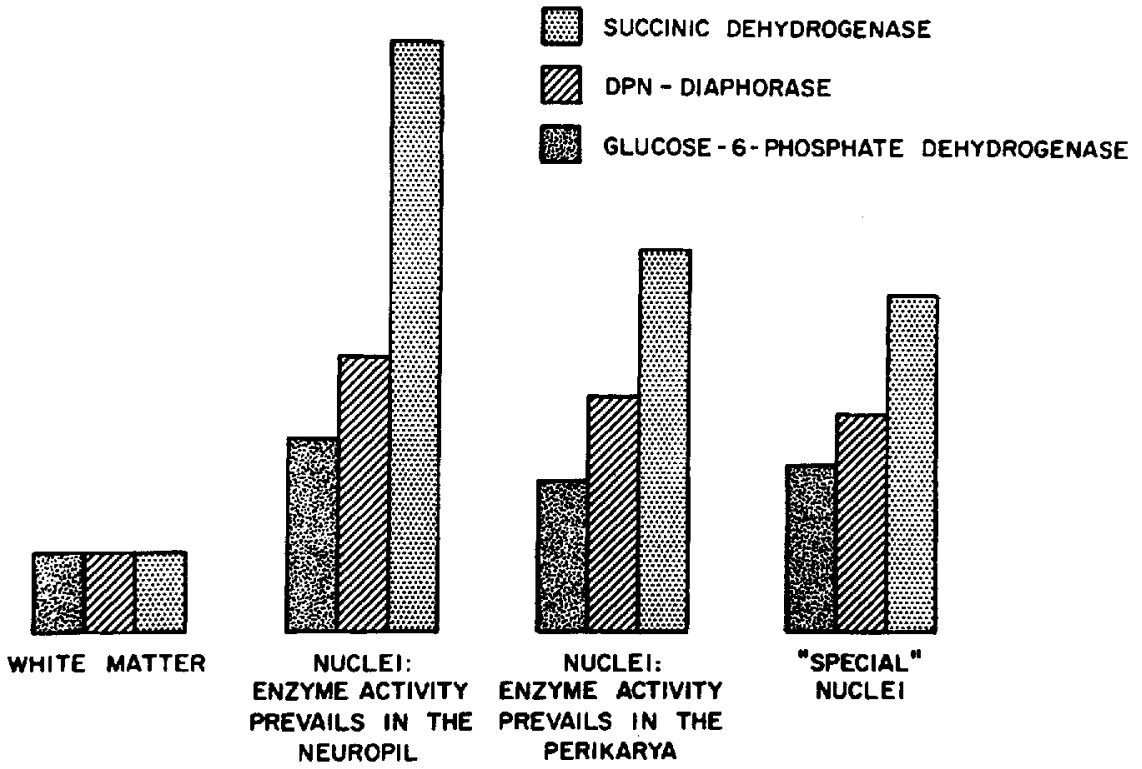

FIG. 6.- 'Average' ratios in assays in homogenates of G-6-P, DPN-diaphorase, and SD from 76 determinations selected at random in monkey brain. For any given area, all three enzymes were determined in triplicate in the same homogenates; activities per wet weight were computed as multiples of that in white matter. The nuclei were classified as to their cytological enzyme distribution. The figure shows that nuclei with much neuropil contain relatively larger ratios of G-6-P, DPN-diaphorase, and SD than nuclei where enzymatic activity predominates in the perikarya. For explanation of the 'special nuclei', see text.

were relatively stronger in "perikarya" nuclei, while the citric acid cycle enzymes were relatively stronger in "neuropil" nuclei. These differences seemed important for comparison of various data when the size of the samples approached cytological level; reduction of sample size tended to obscure the clearcut over-all gradations among nuclei (see discussion).

\section{Gradations between gray and white matter}

White matter always contained less enzyme activity than gray matter. Yet the magnitude of this gradient differed for the individual enzymes. Figure 6 shows a ratio of $1: 2.5$ for G-6-P $1: 3.5$ for DPN-diaphorase, and of $1: 7.6$ for SD in nuclei with enzyme prevalent in neuropil. These observations in monkey brain were consistent with findings in other species. The combination of measurements and microscopic histochemistry permitted one to identify the structures responsible for these different gradients. The oligodendroglia definitely contributed most of the enzyme activity in white matter (Fig. 7), although there was also marked activity in capillaries and somewhat less in axons.

The reaction in oligodendroglia was stronger for G-6-P (Fig. 7) than for any of the other enzymes studied, and thus the gradient between gray and white was smallest for this enzyme. This gradient was markedly larger for $\mathrm{LDH}$ and it increased for the other enzymes in the following order: DPN-diaphorase, MDH, SD, and CYO. As the gradient between gray and white increased for a given enzyme, the reaction in the glia cells was weaker. There was excellent demonstration of glia cells with the LDH 


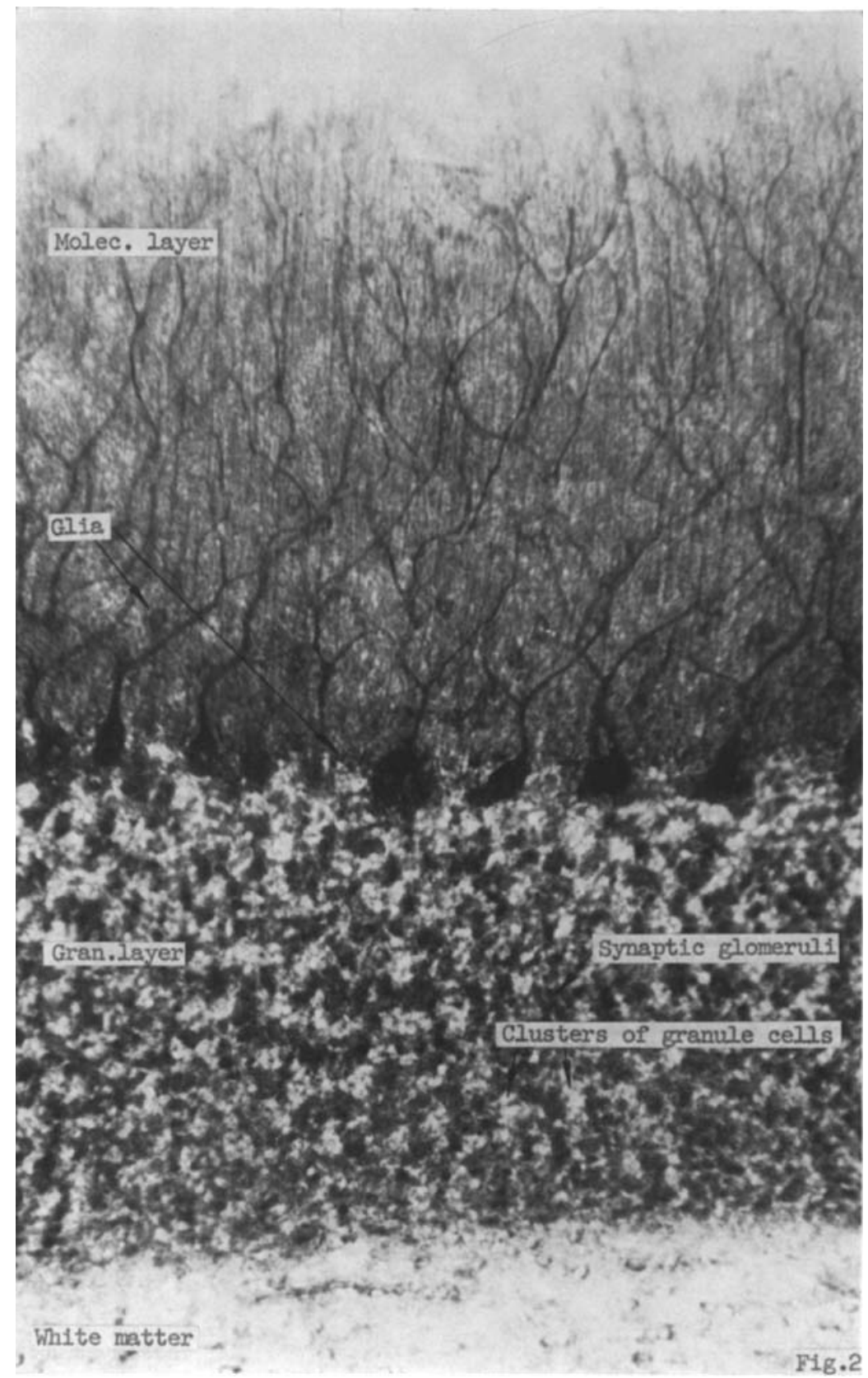

FIG. 2.-Distribution of $\mathrm{LDH}$ in the monkey cerebellar cortex; please compare this picture with Fig. 6 in J. Neurochem. (1962) 9, 190. 


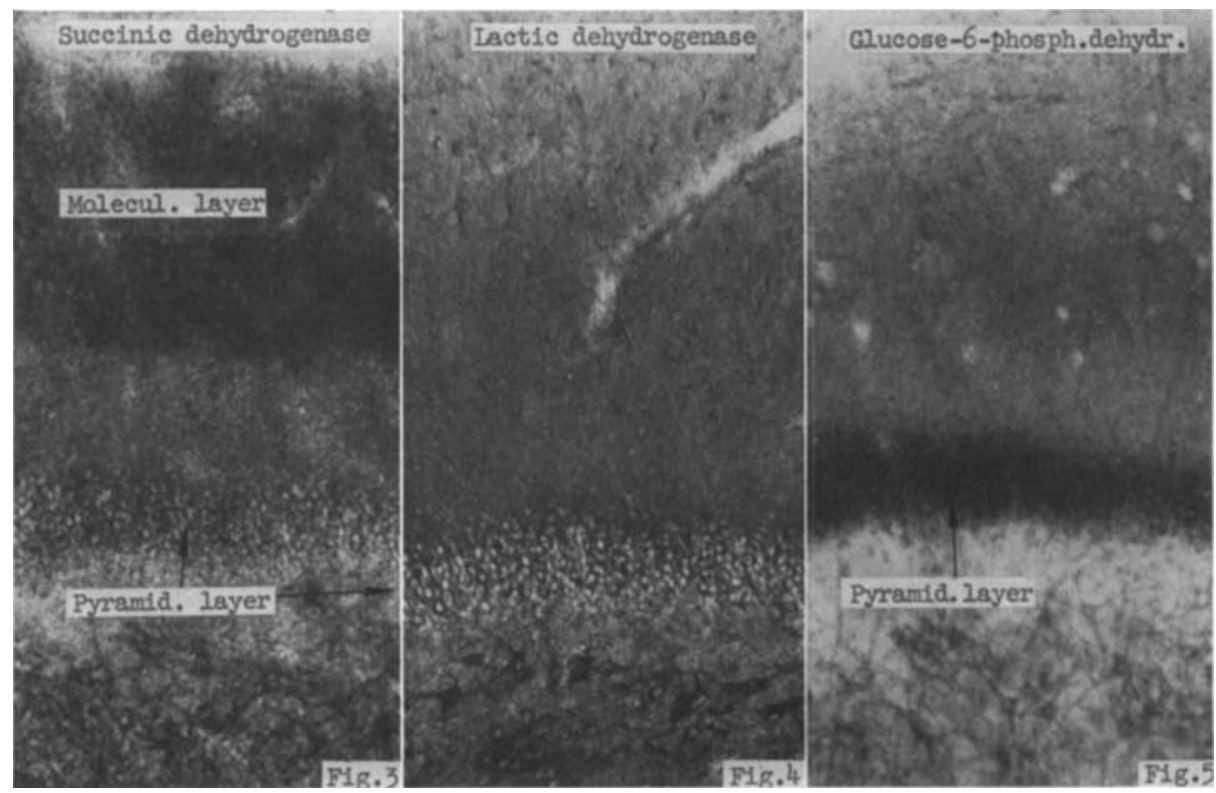

Figs. 3 -5.-Comparison of the distribution of SD (Fig. 3), LDH (Fig. 4), and G-6-P (Fig. 5 ) in the fascia dentata of the monkey. Figs. 3 and 5 represent adjacent sections from the same monkey; $100 x$.

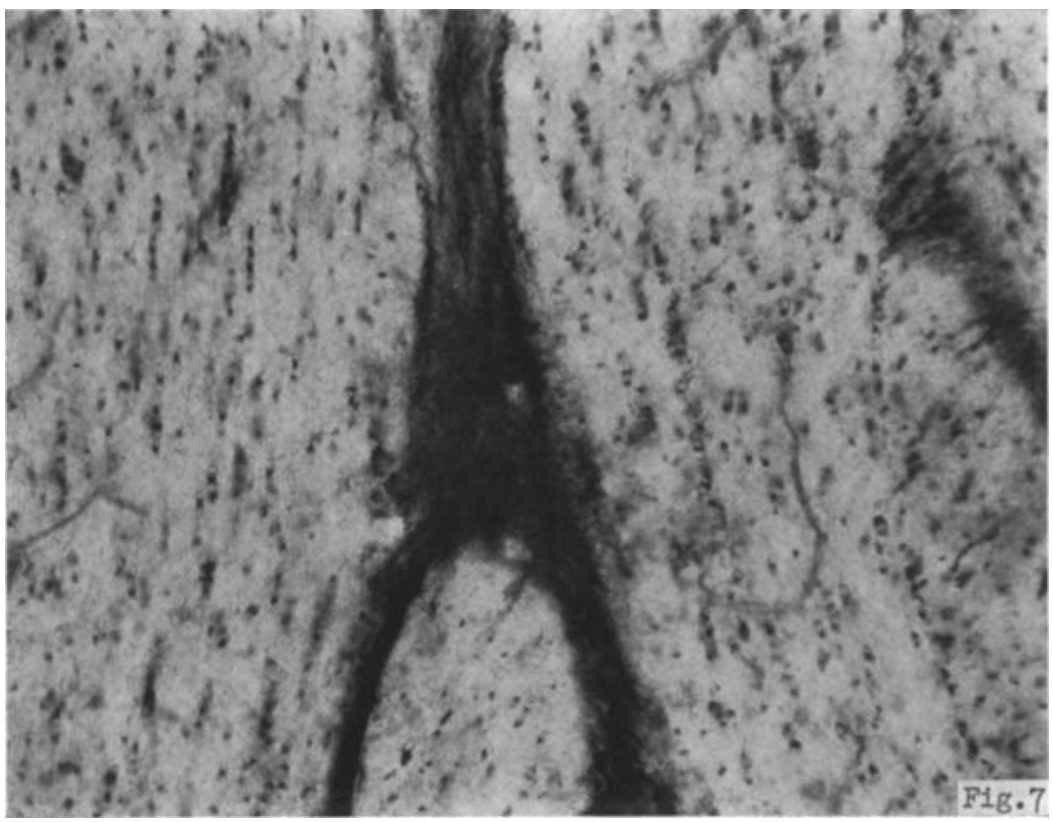

FIG. 7.-Distribution of G-6-P in the human ponto-cerebellar fibre bundles; some pontine gray matter is seen in the centre. The enzyme activity in white matter is localized almost exclusively in oligodendroglia; only a few capillaries are visible and no axons are distinguishable in this field; $130 \times$. 


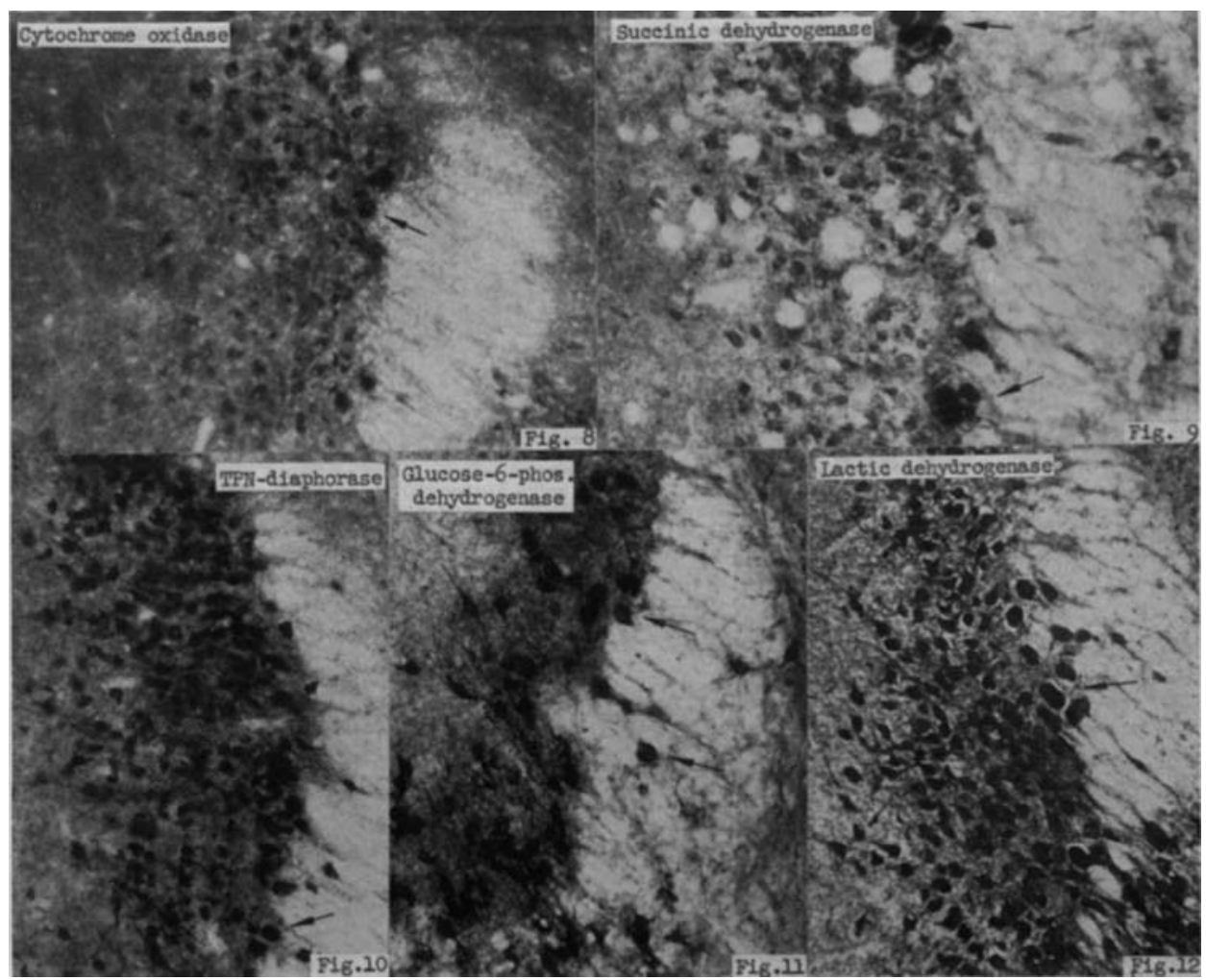

FIGs. 8-12.-Comparison of the distribution of CYO (Fig. 8), SD (Fig. 9), TPNdiaphorase (Fig. 10), G-6-P (Fig. 11), and LDH (Fig. 12) in the nucl. coeruleus of the rhesus monkey. The arrows indicatc some of the spherical cells of the nucleus of the mesencephalic trigeminal root. They may serve as a reference for comparing their reaction with that in the cells of the nucl. coeruleus. In the monkey, the latter contains a little melanin which contributes somewhat to the darkness of the cells in Figs. 9 and 10; the true color reaction is weaker than shown in the black and white prints. All sections, except Fig. 12, represent adjacent sections from the same monkey; $160 \times$.

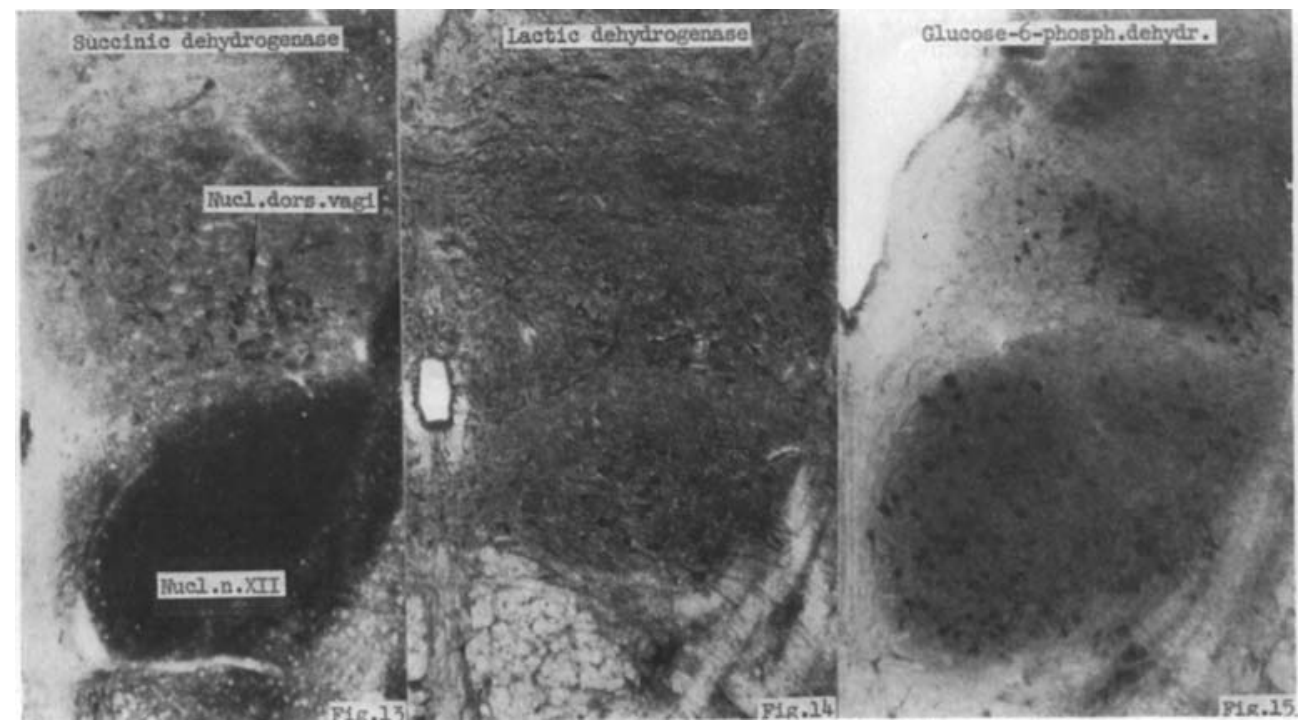

FIGS. 13-15.-Comparison of the gradations of SD (Fig. 13), LDH (Fig. 14), and G-6-P (Fig. 15) in the nucl. hypoglossus and nucl. dorsalis vagi of the rhesus monkey. Figs. 13 and 15 represent adjacent sections from the same monkey; $95 \times$. 
and DPN-diaphorase reactions (FRIEDE, 1961 b), less clear demonstration for MDH, and they were barely distinguishable after a $2 \mathrm{hr}$ incubation for SD or CYO. These differences of enzyme activity in oligodendroglia were paralleled by similar ones in capillaries and to some extent also in axons.

Another point of interest was that man, or larger species, apparently showed stronger enzyme reactions in oligodendroglia than smaller species; likewise, enzyme histochemical differentiation of types of glia cells was much easier in man than in smaller animals.

\section{A system of exceptional nuclei}

There is a group of nuclei in which the comparison of various enzyme distributions was especially interesting because the differences were much more pronounced than elsewhere in gray matter. This group was characterized by very little SD and CYO activity, but extremely strong HMP-shunt enzymes and LDH activity, particularly in the perikarya of the nerve cells. All these nuclei had very little enzyme activity in the neuropil. These exceptional nuclei were: the nucl. dorsalis vagi, the nucl. coeruleus, scattered cell groups near the raphe in the pontine floor of the fourth ventricle, the pars compacta of the substantia nigra, the nucl. supratrochlearis, the nucl. of Edinger-Westphal, the nucl. paraventricularis and supraopticus in the hypothalamus, scattered cell groups in the dorsal and lateral aspects of the hypothalamus, a cell group at the ventral aspect of the pallidum with a small extension between putamen and pallidum, scattered cell groups in the ventral septal area, scattered cell groups dorsal and ventral of the anterior commissure, the subcommissural organ, and the "dorsal crest" in the aqueduct (an area of glial tissue characterized by several histochemical peculiarities, FRIEDE, 1961a). Likewise, the nucleus of the solitary tract contained little SD and CYO, but had strong HMP-shunt enzymes and LDH; however, it differed from the other nuclei listed above in that all enzymes were invariably found in neuropil and none in cell bodies.

This listing of nuclei is arbitrary to a certain extent as one had the impression that there were nuclei which took an intermediary position between the exceptional regions and normal nuclei; e.g. the amygdala and the pars $\mathrm{H} 2$ of the hippocampus. The magnitude of differences seemed to vary somewhat among the nuclei listed above. The nucl. coeruleus, dorsalis vagi, and the hypothalamic nuclei showed the most extreme shifts among enzyme patterns.

Serving as examples, four of the exceptional nuclei are described in detail in the following sections:

Nucleus coeruleus: The exceptional enzyme distribution in the nucl. coeruleus was described best by comparison with the somewhat larger spherical cells of the nucleus of the mesencephalic trigeminal root which were found in close proximity to, or sometimes even interspaced with, the cells of the nucl. coeruleus. The reactions for SD (Fig. 9) and CYO (Fig. 8) were very strong in the trigeminal cells, while the cells of the nucl. coeruleus had very weak enzyme reaction. They were discernible by their different light refraction in the tissue rather than by an enzyme reaction. In man, and to some extent also in the rhesus monkey, these cells were demonstrated by the deposition of melanin in them, but the reaction for SD or CYO was very weak. DPN-diaphorase and TPN-diaphorase (Fig. 10) and LDH (Fig. 12) showed approximately equal staining intensity both in the trigeminal cells and in the cells of the nucl. 
coeruleus. The HMP-shunt enzymes were very strongin the cells of the nucl. coeruleus and distinctly weaker in those of the mesencephalic trigeminal root (Fig. 11). The reaction for the HMP-shunt enzymes and LDH in the nucl. coeruleus was so strong that the nucleus was stained selectively if the staining time was shortened so that the rest of the nuclei had only a very weak reaction.

Nucleus dorsalis vagi: There was some faint reaction for SD and CYO in the nerve cells of the dorsal vagal nucleus (Fig. 13); this was in marked contrast to the strong reaction in both nerve cells and neuropil of the adjacent hypoglossal nucleus (compare FRIEDE, 1961 $c$ plates 3, 4, 6). DPN-diaphorase (compare FRIEDE, 1961 $c$, plate 3), LDH and G-6-P, increasing in that order, were much stronger in the nerve cells of the dorsal vagal nucleus, being equal to (Fig. 14), or even exceeding (Fig. 15), the level in the hypoglossal nucleus. The latter showed only the marked shift of enzyme distribution between neuropil and perikarya which is characteristic for all other nuclei in the brain.

Substantia nigra: The enzyme patterns in this nucleus were noteworthy because of the differences in the pars compacta and the pars reticularis. SD and CY Owere so weak in the pars compacta that the pars reticularis, which showed a medium reaction, was easily mistaken for the whole nucleus (compare FRIEDE, 1961c, plate 17). Such an error was not possible with the reaction for DPN-diaphorase which was almost equal in both parts. There was more LDH and HMP-shunt enzyme activity in the pars compacta.

Nucleus supraopticus and paraventricularis: The reactions for SD and CYO were so light in these two nuclei that they were barely distinguishable from the hypothalamic gray (SHIMIZU, et al., 1957; FRIEDE, 1960a). The reaction for LDH was definitely stronger than the hypothalamic gray, and with the HMP-shunt enzyme reactions these nuclei showed up in marked contrast.

Several of these "exceptional" nuclei were included in the assay data reported in Fig. 6, which shows much smaller differences of enzyme activity than the microscopical studies suggested. This discrepancy was explained by the fact that all of these nuclei were either small or had widely spaced cells. The homogenates, therefore, included much adjacent and interspaced tissue which would tend to level or conceal the exceptional enzyme patterns of the nerve cells.

\section{DISCUSSION}

Several general conclusions may be derived from our data:

(1) Oxidative enzymes of glucose metabolism show almost identical gross distribution among most of the nuclei of brain. This observation is in agreement with the data of RoBINs, et al. (1956b) who found a surprisingly constant relationship of fumarase, MDH, aldolase, and LDH to one another in the cortical layers, except for white matter where the ratios differed. One may presuppose that the local concentration of a given enzyme indicates the capacity for metabolism along the pathway on which that enzyme is involved; if this is true, all members of the pathway should vary in a constant ratio (BuELL, et al., 1958). This postulate seems to be fully supported by the data in Table 1 . Indeed, the correlations in Table 1 and Fig. 1 seem more striking than those observed in microchemical studies. This better correlation evidently resulted from the fact that enzyme distributions in whole nuclei, rather than in their cellular components, were compared with each other (see below). 
The relative gradations of enzyme distribution among a large sampling of nuclei and areas seem to establish a more dependable baseline for chemoarchitecture than absolute measurements do. The absolute (molar) activity varied greatly for the individual enzymes studied; the capacity for the hexosemonophosphate (HMP)shunt was quite small as compared with reactions for the enzymes of the EMBDENMeYerhof pathway (HotTA, 1962). Yet the relative distribution among nuclei, even for remotely related enzymes, was amazingly similar.

There is a marked species difference in respiration, enzyme activity and capillarization per volume of brain tissue (ElliotT, 1948; KreBs, 1950; FrIED and TiPTON, 1953; LOCKER and KAPS, 1960; FRIEDE, 1961c); all vary inversely with body size. However, the relative gradations of enzymes between nuclei in the medulla compared very well among species (Table 1), even though absolute quantities were markedly different. Therefore, it was concluded that systematic mappings of enzyme activities, such as have been done in this laboratory, provide a reliable parameter of relative differences of energy metabolism among nuclei.

(2) Oligodendroglia in white matter contain relatively more hexosemonophosphateshunt enzymes and $L D H$ and relatively less citric acid cycle enzymes than gray matter. This explains to a great extent the different gradations of enzyme activities between white and gray matter. The microscopic observations showed precisely which structures were responsible for the differences that were observed in assays or spectrophotometric measurements; these measurements were in keeping with data reported in the literature.

For the third layer of the frontal cortex, the following ratios of enzyme distri, bution between white and gray matter were reported (Hess and PoPE, 1960; RoBINSSMith, EYdT and MCCAMAn, 1956b; WeINER, 1960; and others:

$\begin{array}{lll}\text { CYO } & 1: 5 \cdot 0-5 \cdot 7 & \text { (man) } \\ \text { SD } & 1: 4 \cdot 3-2 \cdot 4 & \text { (cow, dog; whole cortex!) } \\ \text { Fumarase and MDH } & 1: 3 \cdot 0-4 \cdot 1 & \text { (monkey) } \\ \text { Aldolase and LDH } & 1: 1 \cdot 7-2 \cdot 3 & \end{array}$

The cerebellar cortex showed the following ratios of white matter/molecular layer (RoBINS and SMITH, 1953; dry weight)

$\begin{array}{ll}\text { Fumarase } & 1: 7 \cdot 2 \\ \text { MDH } & 1: 3 \cdot 3 \\ \text { Aldolase } & 1: 3 \cdot 0 \\ \text { LDH } & 1: 2 \cdot 8\end{array}$

Microchemical gradients in other regions, such as ammonshorn (LowRy et al., 1954; BuELL, et al., 1958), indicate a similar trend. Approximately the same ratios were observed in our material when white matter and "neuropil" nuclei (Fig. 6) were compared:

$$
\begin{array}{ll}
\text { SD } & 1: 7 \cdot 6 \\
\text { DPN-diaphorase } & 1: 3.5 \\
\text { G-6-P } & 1: 2.5
\end{array}
$$

When these ratios of enzyme distribution in white and gray matter were compared with the cytological distribution of enzyme activity, it became apparent that several 
tissue structures were making variable contributions to the total activity. By far the greatest enzyme reaction in white matter, particularly that for G-6-P, was in the oligodendroglia cells. There was some reaction in capillaries but still less in the axons. This relative enzyme gradient between nerve cells and glia has been reported by Romanul and CoHEN (1960).

Therefore, the suggestion that glycolysis assumes a relatively more important role in white matter than it does in gray matter (RoBINS and SMITH, 1953; RoBINS, et al., 1956a; RoBINS, et al., 1956b) actually applies mainly to oligodendroglia (POPE and Hess, 1957); to a lesser extent it also includes capillaries and axons. However, it has been shown that the number of glia cells, as well as the relative proportion of total DPN-diaphorase contributed by glia or axons, varies greatly among tracts (FRIEDE, 1961b). In addition, the enzyme supply contributed by oligodendroglia cells depends on what type they are. Types 3 and 4 had stronger enzyme activity than types 1 and 2 (FRIEDE, 1961b). The estimate that axoplasmic constituents contribute one-third to the respiration of white matter (KOREY and OrCHeN, 1959) certainly cannot be generalized. The quantitative and even qualitative differences of enzyme distribution between oligodendroglia and axons in various tracts may account for the quantitative differences of G-6-P and other enzymes among central tracts (BUELL et al., 1958; MCDougal, 1958; RoBins, 1960; MCDougal et al., 1961). There is no histochemical evidence for the proposed relationship of enzyme distribution to the nodes of Ranvier as suggested by MCDougal (1958), RoBins (1960), and MCDOUGAL, et al.(1961). In peripheral nerves, the nodes of Ranvier show strongactivity of SD, TPN-diaphorase and DPN-diaphorase (FrIEDE, 1959b). In the CNS, however, there was no comparable histochemical demonstration of the nodes by enzyme activity, so the latter can be disregarded as a source of enzyme activity in white matter.

Histochemical observations of glia cells in the cerebellar cortex (compare results para. B) suggest that the above conclusion regarding oligodendroglia in white matter apply to all oligodendroglia cells. Data of HYDÉN and PIGON (1960) and HYDÉN and LANGE $(1961,1962)$ suggest that, upon stimulation, nerve cells increase their aerobic metabolism while the glia metabolism resorts partly to anaerobic glycolysis. Likewise the cytological patterns described in this article are paralleled by the different gradients of HMP-shunt enzymes and CA cycle enzymes in nerve and capsule cells of spinal ganglia (LOWRY, 1957) and of succinic oxidase and CYO in spinal ganglia (HydÉN, LøVTRUP and PIGON, 1958), and the different rates of utilization of glutamate, succinate and pyruvate by such cells (HAMBERGER, 1961).

(3) While over-all gradations of enzymatic activities among nuclei were nearly identical, there were marked differences in the distribution of the various enzymes in the cytological compartments of any given nucleus: In particular, enzymes of the HMPshunt prevailed relatively in perikarya while enzymes of the CA-cycle prevailed in neuropil. Analogous differences between the distributions of DPN-diaphorase and SD have been observed in preceding studies (FrIEDE, 1961c). Such cytological differences in enzyme distribution have to be distinguished from the over-all gradations of enzyme activities among nuclei, particularly when comparing microchemical measurements in various regions.

The correlation coefficients for comparison of the distribution of various enzymes among whole nuclei were nearly perfect. This agreed with Robins et al. (1956b) who 
compared cortical laminae which, in many ways, are homologous to nuclei.' Within nuclei or cell populations, however, various metabolic phases are localized in certain cell compartments; likewise, the cytological localization of a particular enzyme varies among nuclei. This means that the good correlation of enzyme distribution among nuclei will decrease more and more as the sample size is scaled down to the cytological level. For example, if every set of data for SD and DPN-diaphorase in Table 1 could be reported separately for neuropil and for perikarya, very poor correlation coefficients would result.

This consideration explains why this study showed a correlation coefficient of 0.72 to 0.76 , even between the distributions of $\mathrm{G}-6-\mathrm{P}$ and those of the other enzymes, while microchemical data on ammonshorn (STROMINGER and LOWRY, 1955; BUELL et al., 1958), cerebellar cortex (RoBINs and SMITH, 1953; RoBINs et al., 1957), and other regions (LowRY et al., 1956) would not seem to suggest any similarity of distribution among these enzymes.

Similar cytological compartmentalization of enzymes has been reported. Lowry, et al. (1956) observed a reciprocal relationship of $\mathrm{LDH}$ and $\mathrm{MDH}$ in the retina; the $\mathrm{MDH}$ was highest in the outer layers, the $\mathrm{LDH}$ vice versa. Histochemically, CYO and SD showed maximun reaction in the outer layers of the retina, while DPN-diaphorase and LDH prevailed in the ganglion cell layers (NIEMI and MERENMIES, 1961 $a, b$ ).

Schwann cells have been shown to exhibit SD almost exclusively at their most distal cytoplasmic extension at the nodes of Ranvier, while TPN-diaphorase and, particularly, DPN-diaphorase activities were found both at the nodes and in the perikarya (FRIEDE, 1959a).

Measurements of the cerebellar granular layer (RoBINs et al., 1957) are not representative for perikarya. Although the synaptic glomeruli occupy about onetwentieth of the total volume of the layer (FRIEDE, 1963), they are extremely rich in CA cycle enzymes and represent almost the total supply of these enzymes for that layer (FrIEDE, 1959a, 1961c; LAzARUs et al., 1962).

In comparing microchemical and histochemical data, it is important to realize that histochemical data refer to volume or wet weight, while microchemical data often refer to fat-free dry weight. For example, the data by BuELL et al. (1958) show a ratio of 1:0.73 for G-6-P in dendrite layer and cell layer of the ammonshorn. With correction for the lipid content, this ratio changes to $1: 1.64$; this is in better agreement with the histochemical preparations which showed greater reaction in the cells. If this corrected ratio is compared with that for LDH and MDH in the ammonshorn (STROMINGER and LOWRY, 1955), the ratios of the individual enzymes agree with the cytological patterns described in this article. RoBINs (1960) reports lower enzymatic activities in anterior horn nerve cells than in neuropil; these data also refer to fat-free dry weight. This explains why the histochemical gradient per volume is inverse, showing a stronger reaction in the cells than in the neuropil.

We considered it more useful to refer to volume for histochemistry, and to wetweight for assays of enzyme activities (FoLCH-PI, 1953) than to report it as fat-free dry-weight or as amount of protein. Our studies always included a description of the activity within a specific volume and, as far as we know, metabolites are offered to a volume of tissue and not selectively to the proteins in it. Also, we have seen that enzyme activities/volume are proportional to capillarization/volume, while such a relationship has never been shown on the basis of protein or fat-free dry weight. 
(4) A small group of nuclei is characterized by extremely high activity of hexosemonophosphate-shunt enzymes and $L D H$ and a very little $S D$ and $C Y O$. Strong activity of a given enzyme in a nucleus does not prove that this enzyme is being used to capacity; however, very little activity of an enzyme indicates that the related metabolic pathway is not available to the same extent that it is in other nuclei. Therefore, the CA cycle in these exceptional nuclei is not utilized to the same extent as in other nuclei. The marked activity of HMP-shunt enzymes and LDH strongly suggests that these nuclei are characterized by a relative predominance of the HMP-shunt and/or anaerobic glycolytic metabolism. The data by STROMINGER and LOWRY (1955) may be quoted in support; they show in hypothalamus and supraoptic nucleus the highest ratio of $\mathrm{MDH} / \mathrm{LDH}$ among all measured nuclei of the brain. The exceptional nuclei also had more capillaries per volume than would be expected from the general relationship between capillarization and SD (FrIEDE, 1961c).

Several other observations suggested exceptional metabolism in this group of nuclei. For example, these nuclei were characterized by very strong monoamine oxidase activity as shown by HASHIMOTо et al. (1962) in a detailed histochemical mapping of the distribution of this enzyme. Several observations of an exceptional resistance of these nuclei to anoxia, such as for the dorsal vagal nucleus (KaLle, 1933; HeYmans et al., 1934, 1938) and the nucl. supraopticus and parave ntricularis (GRENELL and KABAT, 1947), seem to support the concept of a predominantly glycolytic metabolism in them. Physiologically, most of these nuclei have autonomic functions.

\section{SUMMARY}

This paper submits a comparison of the distribution in the brain of seven enzymes related to glucose metabolism. The data were obtained partly with histochemical and partly with assay methods. The following general conclusions were derived from a comparison of the data:

(1). The patterns of a number of oxidative enzymes are almost identical among most of the nuclei of the brain; they also are similar among species, particularly in the medulla oblongata. In spite of these nearly identical gradations among nuclei, there were marked differences in the cytological distributions of various enzymes within any given nucleus.

(2) Differences in enzyme distribution suggest that the perikarya of nerve cells utilize hexosemonophosphate-shunt and glycolytic metabolism to a relatively larger extent than the dendrites or neuropil.

(3) Oligodendroglia in white matter contain relatively much more hexosemonophosphate-shunt enzymes and less citric acid cycle enzymes than nerve cells.

(4) A system of nuclei in the brain was described, characterized by high activity of lactic dehydrogenase and hexosemonophosphate-shunt enzymes and very little succinic dehydrogenase and cytochrome oxidase. These nuclei probably depend mostly on anaerobic and hexosemonophosphate-shunt metabolism.

\section{REFERENCES}

Buell M. V., Lowry O. H., Roberts N. R., Chang M.-L. W. and Kapphahn J. I. (1958) J. biol. Chem. 232, 979.

Elliott K. A. G. (1948) $J$. Neurophysiol. 11, 437.

Folch-Pi J. (1953) Res. Publ. Ass, nerv. ment. Dis. 32, p. 322.

Fried G. H., and Tipton S. R. (1953) Proc. Soc. exp. Biol. 82, 531. 
FRIEDE R. L. (1959a) J. Neurochem. 4, 111 and 290.

FRIEDE R. L. (1959b) Exp. Neurol. 1, 441.

FrJede R. L. (1960a) J. Neurochem. 5, 156 and 190.

FRIEDE R. L. (1960b) In Regional Neurochemistry (Edited by Kety S. S. and Elkes J.) p. 151. Pergamon Press, Oxford.

FRIEDE R. L. (1961a) J. comp. Neurol. 116, 229.

FRIEDE R. L. (1961b) J. Neurochem. 8, 17.

FrIEDE R. L. (1961c) A Histochemical Atlas of Tissue Oxidation in the Brain Stem of the Cat. S. Karger, Basel and New York.

Friede R. L., and Fleming L. M. (1962) J. Neurochem. 9, 179.

FRIEDE R. L. (1963) Arch. Neurol. (Chic.) 3, 67.

Friede R. L., Fleming L. M., and Knoller M. (1963) J. Histochem. Cytochem. (in press).

Grenell R. G. and Kabat H. (1947) J. Neuropath. exp. Neurol. 6, 35.

HAMBerger A. (1961) J. Neurochem. 8, 31.

Hashimoto P. H., MaEda T., TorII K. and Shmizu N. (1962) Med. J. Osaka Univ. 12, 425.

Heymans C., Jourdan F, and Nova K. S. J. G. (1934) C.R. Soc. Biol. (Paris) 117, 478.

Heymans C., Boukaert J. J., Jourdan F., Novak S. J. G. and Farber S. (1938) Arch. Neurol. Psychiat. (Chic.) 38, 304.

Hess H. H. and Pope A. (1960) J. Neurochem. 5, 207.

HotTA S. S. (1962) J. Neurochem. 9, 43.

Hydén H., Løvtrup S. and Pigon A. (1958) J. Neurochem. 2, 304.

HYdéN H. and Pigon A. (1960) J. Neurochem. 6, 57.

Hydén H. and LANGe P. (1961) In Regional Neurochemistry. (Edited by Kety S. S. and Elkes J.) p. 190. Pergamon Press, Oxford.

Hydén H. and LANGe P. W. (1962) J. Cell. Biol. 13, 233.

KaLle E. (1933) Disch. Z. ges. gerichtl. Med. 22, 192.

KoreY S. R. and ORCHEN M. (1959) J. Neurochem. 3, 277.

KreBs H. A. (1950) Biochem. biophys. Acta 4, 249.

Lazarus S. S., Wallace B. J., EdGar G. W. F. and Volk B. W. (1962) J. Neurochem. 9, 227.

LOCKer A. and KAPS R. M. (1960) Z. ges. exp. Med. 134, 29.

LowRY O. H. (1957) In Metabolism of the Nervous System. (Edited by Richter D.) p. 323. Pergamon Press, London.

Lowry O. H., Roberts N. R., Leiner K. Y., Wu M., FARR A. L. and Albers R. W. (1954) J. biol. Chem. 207, 39.

Lowry O. H., Roberts N. R. and Lewis C. (1956) J. biol. Chem. 220, 879.

MCDougal D. B., Jr. (1958) Neurology (Minneap.) 8, 58.

McDougal D. B. Jr., Schulz D. W., Passonneau J. V., Clark J. R., Reynolos M. A. and Lowry O. H. (1961) J. gen. Physiol. 44, 487.

Niemi M. and Merenmies E. (1961a) J. Neurochem. 6, 200.

NiEmi M. and MERENMIEs E. (1961b) J. Neurochem. 6, 206.

Pope A. and Hess H. H. (1957) In Metabolism of the Nervous System. (Edited by Richter D.) p. 72. Pergamon Press, London.

RobIns E. and Smirh D. E. (1953) In Res. Publ. Ass. nerv. ment. Dis. Vol. 32. Chap. XVI.

Robins E., SMITH D. E. and JEN M. K. (1957) In Progress in Neurobiology, II. (Edited by Waelsch H.) Chap. XI. Hoeber-Harper, New York.

Robins E., Roberts N. R., EYdT K. M., Lowry O. H. and SMITH D. E. (1956a) J. biol. Chem. $218,897$.

Robins E., Smith D. E., Eydt K. M. and MCCAMAN R. E. (1956b) J. Neurochem. 1, 68.

RoBrns E. (1960) J. Histochem. Cytochem. 8, 431.

Romanul F. and Cohen R. B. (1960) J. Neuropath. exp. Neurol. 19, 35.

SHImizu N., Morikawa N. and IshI Y. (1957) J. comp. Neurol. 108, 1.

STROMINGER J. L. and Lowry O. H. (1955) J. biol. Chem. 213, 635.

WEINER N. (1960) J. Neurochem. 6, 79.

\section{APPENDIX}

Histochemical measurements of lactic dehydrogenase activity in the nuclei and in regions of the brain of the rhesus monkey.

The measurements indicate $\mu \mathrm{g}$ formazan $/ 0.131 \mathrm{~mm}^{3}$ tissue $/ 2$ hours at $38^{\circ}$ in $30 \mu$ sections of formalin fixed ( 24 hours, $4^{\circ}$ ) tissue. They represent averages from a total of 2014 measurements in three monkey brains. (All measurements from the second and third brains were corrected with a given factor to compensate for the different ratio of volumes of tissue and incubation fluid (see FRIEDE, FLEMING and KNOLLER, 1962).) An effort was made to represent all nuclei by approximately equal numbers of measurements in all brains. 
Columna ventralis

Medulla spinalis

Columna lateralis

$52 \pm 3$

Lateral tracts

$54 \pm 2$

Dorsal tracts

$21 \pm 5$

Medulla oblongata

N. cuneatus medialis

$55 \pm 6$

N. cuneatus lateralis

$58 \pm 5$

N. tractus desc. n. trigemini (gen. region)

$44 \pm 6$

N. nervi hypoglossi

$49 \pm 5$

N. tractus solitarii

$35 \pm 11$

N. reticularis

N. reticularis lateralis

$38 \pm 5$

$52+6$

$\mathrm{N}$. vestibularis medialis

$55 \pm 6$

$\mathrm{N}$. vestibularis lateralis

$46+5$

$47 \pm 7$

$16 \pm 1$

N. prepositus hypoglossi

$20 \pm 2$

Corpus restiforme

N. nervi facialis

$\mathrm{N}$. reticularis gigantocellularis

$50 \div 4$

$41 \pm 3$

Nervus $V$

$14 \pm 2$

\section{Cerebellum}

Cortex (whole)

N. fastigii

N. dentatus

Substantia alba

$49+11$

$35 \pm 9$

$52+7$

$19 \pm 3$

Pons

Nucl. reticularis

$36 \pm 3$

N. nervi abducentis

$62 \pm 4$

Griseum centrale

$N$. coeruleus and griseum centrale

$42+7$

$37 \pm 4$

$59 \pm 6$

$40 \pm 2$

N. parabrachialis

$40 \pm 2$
$59 \pm 4$

$\mathrm{N}$. parolivaris and $\mathrm{n}$. olivaris superior

$44 \pm 4$

N. reticularis Bechterew (retic. portion)

$50 \div 6$

N. pontis (retic. portion)

Brachia pontis

Brachium conjunctivum

$17 \pm 3$

$22+2$

N. lemnisci lateralis

$46 \pm 2$

Midbrain (colliculus inf.)

Colliculus posterior (caudal portion)

Griseum centrale (ventral portion)

$74+4$

Midline nuclei

N. mesencephalicus profundus

Midbrain (colliculus sup.)

Colliculus superior (laminae profundae)

$43+6$

Regio S

$36 \pm 3$

Griseum centrale (dorsolateral portion)

$44 \pm 4$

Griseum centrale (ventromedial portion)

$39+5$

Pretectal area

$38 \pm 5$

N. nervi oculomotorii

$64 \pm 5$

$N$. ruber

$N$. niger

Pedunculi cerebri

$42 \pm 4$

$38 \div 5$

$17 \leftarrow 2$

$\mathrm{N}$. interpeduncularis 
Diencephalon (thalamus)

N. anterior (dorsalis)

$48 \pm 9$

N. lateralis

$39 \pm 5$

N. dorsomedialis

$41 \pm 5$

Anterior midline nuclei

$37 \pm 3$

Centre median

$32 \pm 3$

Midline-nuclear group (deep transition into hypothalamus)

$30 \pm 3$

Pulvinar

$37 \pm 4$

N. geniculatus medialis

$43 \pm 4$

N. geniculatus lateralis

$41 \pm 6$

Capsula interna

Tractus opticus

$18 \pm 2$

$19 \pm 3$

N. reticularis thalami

$39 \pm 3$

Tuber cinereum

Diencephalon (subthal. centres)

N. subthalamicus

Zona incerta

Peduncular zone of $\mathrm{n}$. intercalatus

$44 \pm 4$

$51 \pm 11$

$35 \pm 4$

$30 \pm 4$

Commissura anterior

$21 \pm 4$

Corpus callosum

$17 \pm 2$

N. caudatus (caput)

Basal telencephalic centres

Putamen

$49+8$

Pallidum externum

$54 \pm 6$

$33 \pm 2$

Pallidum internum

$36 \pm 4$

Capsula interna

Claustrum

$18 \pm 2$

$35+12$

Amygdala

$33 \pm 5$

Septal region

$41 \pm 7$

Laminae II-IV

Precentral motor cortex

Laminae II-IV

Frontal pole

Substantia alba

Parictal cortex

Laminae II-IV

Substantia alba

Insular cortex

$17 \pm 3$

$43 \pm 6$

Area 18, laminae II-IV

Occipital cortex

$44 \pm 5$

$40 \pm 5$

$20 \pm 2$

Area 17, lamina IV

$59 \pm 9$

71 t上 6

Substantia alba

$17+2$

Laminae II-IV

Temporal cortex

$39 \pm 4$

Substantia alba

$21 \pm 3$

Laminae IT-TV

Deep temporal cortex

Substantia alba

$18 \pm 2$

$45 \pm 5$

Subiculum

$36 \pm 2$ 